\title{
General Anesthesia in Geriatric Dogs with Propofol-Isoflurane, Propofol- Sevoflurane, Alphaxalone-Isoflurane, Alphaxalone-Sevoflurane and Their Comparison of Biochemical, Hemodynamic and Cardiopulmonary Effects
}

\author{
Zeynep Bilgen Şen \& Nuh Kiliç
}

\begin{abstract}
Background: Geriatric is defined as the life-cycle in which the physical state, organ functions, sensory functions, mental function and immunity progressively regress. Aging causes progressive and irreversible changes in the functional capacities of organ systems, which in turn alter the response to stress and anesthetic drugs. Propofol is an anesthetic agent with sedative and hypnotic effects. Anesthesia induction with propofol is fast and smooth. Alphaxalone ( $3 \alpha$-hydroxy-5 $\alpha$-pregnane11,20-dione) is a central nervous system depressant in the form of synthetic neuroactive steroids. This allows anesthesia and muscle relaxation by increasing the inhibition of gamma amino butyric acid type A (GABA) receptors. The aim of this study is to compare effects of propofol-isoflurane and propofol-sevoflurane with relatively a new anesthetic combination alphaxalone-isoflurane and alphaxalone-sevoflurane on hematological, biochemical and physiological parameters.

Materials, Methods \& Results: Dogs were randomly divided into 4 groups and anesthesia protocols were applied. After induction of anesthesia with $6 \mathrm{mg} / \mathrm{kg}$ propofol in groups 1 and 2, isoflurane anesthesia was continued in group 1 and sevoflurane in group 2. After induction of $3 \mathrm{mg} / \mathrm{kg}$ alphaxalone anesthesia in groups 3 and 4 , isoflurane anesthesia was continued in group 3 whereas sevoflurane in group 4 . Vena cephalica was catheterized for blood collection. At the preanesthetic period, 15, 30, 45, $60 \mathrm{~min}$ and $60 \mathrm{~min}$ after the anesthesia, complete blood counts were performed. Serum ALT, AST, urea, creatinine values were measured during preanesthesia, perianesthesia 15-30 min and $60 \mathrm{~min}$ after anesthesia. Cardiopulmonary parameters and reflexes were evaluated before anesthesia and recorded at perianesthetic 5, 10, 15, 30, 45, $60 \mathrm{~min}$ and $60 \mathrm{~min}$ after full recovery. Patients were monitored during anesthesia. The average age of the dogs in the study was 10.83. All of the dogs were anesthetized in a few seconds with intravenous injection of propofol or alphaxalone. During anesthesia the respiratory rate $\left(f_{\mathrm{R}}\right)$ was recorded by counting the movements of the reservoir bag. A pulse oximeter was used to monitor pulse rate $\left(f_{\mathrm{H}}\right)$ and haemoglobin oxygen saturation $\left(\mathrm{SpO}_{2}\right)$. Body temperature was measured from rectum with a thermometer. Geriatric dogs were anesthetized for a variety of clinical reasons, concerning laparatomy $(12.5 \%)$, orthopedic $(7.5 \%)$, soft tissue $(60 \%)$, dental (10\%) and ophthalmologic surgery (10\%). Duration of anesthesia was 94.44 ( \pm 12.6$)$ for group I, 81 ( \pm 10.54$)$ for group II, 93.88 ( \pm 11.6$)$ for group III and $64.5( \pm 3.97)$ min for group IV. Serum urea and creatinine concentrations were not significantly different in the four groups.

Discussion: The mean duration of anesthesia recovery was $6.0 \pm 2.0$ in group $1,4.6 \pm 1.45$ in group 2, $3.7 \pm 1.23$ in group 3 and $9.7 \pm 3.09 \mathrm{~min}$ in group 4 . In group 4 recovery was longer than other groups and statistically significant $(P<0.05)$. In our research, the recovery is shorter in the isoflurane treated groups than in the sevoflurane treated groups. When the effect of different groups on heart rate was examined, the difference between them was not significant. Duration and depth of the anesthesia with propofol-isoflurane, propofol-sevoflurane, alphaxalone-isoflurane and alphaxalone-sevoflurane were found to be satisfactory for surgery. Four anesthetic agents applied in geriatric dogs did not adversely affected the hematological and biochemical parameters. In conclusion anesthesia on geriatric dogs after induction of propofol and alphaxalone maintained with isoflurane or sevoflurane found to be safe. However, they did not provide analgesia in painful operations, so it would be appropriate to use analgesics in the pre or intraoperative period.
\end{abstract}

Keywords: propofol, alphaxalone, isoflurane, sevoflurane, dog, geriatric. com - Fax: +90 (256) 2470700]. Department of Surgery, Faculty of Veterinary, Adnan Menderes University, Isikli. Aydin 09017, Turkey. 


\section{INTRODUCTION}

Geriatric is defined as the life-cycle in which the physical state, organ functions, sensory functions, mental function and immunity progressively regress. [10]. Aging causes progressive and irreversible changes in the functional capacities of organ systems, which in turn alter the response to stress and anesthetic drugs [6]. Respiratory functions like lung elasticity, resistance, inspiratory and vital capacity are decreasing [19,23]. In geriatric patients hepatic metabolizing capacity is reduced [8]. Renal blood flow, glomerular filtration, tubular function, and creatinin clearance is reduced in diseased animals [26].

Propofol is an anesthetic agent with sedative and hypnotic effects [33]. Anesthesia induction with propofol is fast and smooth. It is also a useful agent for induction of anesthesia in geriatric patients [24].

Alphaxalone is a central nervous system depressant in the form of synthetic neuroactive steroids. This allows anesthesia and muscle relaxation by increasing the inhibition of gamma amino butyric acid type A (GABA) receptors [1,14]. Alphaxalone first started to be used in 1971 with the name alphadolone, a neuroactive steroid. This formula has been used in humans and veterinary medicine but severe side effects such as anaphylactic reactions have occurred [32]. Alphaxalone provides rapid, smooth and effective induction of anesthesia. Recovery from anesthesia is similar to that of propofol [30].

The objectives of this study is to determine the effect of these anesthetics on hematological, biochemical and physiological parameters in geriatric dogs and thus determine which anesthetic agent is safer or superior in geriatric patients.

\section{MATERIALS AND METHODS}

\section{Geriatric patients}

Forty geriatric dogs undergoing general anesthesia for variety of clinical reasons in Adnan Menderes University Veterinary Faculty Surgery Departement were enrolled in the study. Dogs were withheld from food for $12 \mathrm{~h}$ before anesthesia. The anamnesis of all geriatric dogs rested and a full clinical examination including inspection of the colour of the mucous membranes, abdominal palpation, thoracic auscultation, lymph node examination, measurements of respiratory rate $\left(f_{\mathrm{R}}\right)$, heart rate $\left(f_{\mathrm{H}}\right)$, and rectal temperature
(T). Subsequently withdrawal, ear, tail, rear and hind pedal, pupillar reflexes were assessed. Vena cephalica was catheterized for blood collection.

Anesthesia protocols and data collection

Dogs were randomly placed into 4 groups and anesthesia protocols were applied. After induction of anesthesia with $6 \mathrm{mg} / \mathrm{kg}$ propofol (Propofol $\left.1 \%{ }^{\circledR}\right)^{1}$ in groups 1 and 2, isoflurane anesthesia was continued in group 1 and sevoflurane in group 2. After induction of $3 \mathrm{mg} / \mathrm{kg}$ alphaxalone $\left(\text { Alfaxan }^{\circledR}\right)^{2}$ anesthesia in groups 3 and 4 , isoflurane (Isoflurane $\left.{ }^{\circledR}\right)^{3}$ anesthesia was continued in group 3 whereas sevoflurane (Sevorane Likit $\left.{ }^{\circledR}\right)^{4}$ in group 4. Anesthesia was maintained with $2-4 \%$ isoflurane or $4-6 \%$ sevoflurane delivered in 100 per cent oxygen. At the preanesthetic period, 15, 30, 45, $60 \mathrm{~min}$ and $60 \mathrm{~min}$ after the anesthesia, complete blood counts were performed (Abacus Junior Vet 5) ${ }^{5}$. Serum ALT, AST, urea, creatinine values were measured (Reflotron Plus $)^{6}$ during preanesthesia, perianesthesia 15-30 min and 60 min after anesthesia. Cardiopulmonary parameters and reflexes were evaluated before anesthesia and recorded at perianesthetic 5, 10, 15, 30, 45, $60 \mathrm{~min}$ and $60 \mathrm{~min}$ after full recovery.

All dogs were intubated with a endotracheal tube after propofol or alphaxalone induction. During anesthesia the respiratory rate $\left(f_{\mathrm{R}}\right)$ was recorded by counting the movements of the reservoir bag. A pulse oximeter was used to monitor pulse rate (fH) and haemoglobin oxygen saturation $\left(\mathrm{SpO}_{2}\right)$. Body temperature was measured from rectum with a thermometer.

At the end of surgery, isoflurane or sevoflurane administration was ceased. Endotracheal tube was extubated when swallowing reflex was noticed. All anaesthetics were administered by a single anaesthetist like the assesment of the quality of the recoveries.

\section{Statistical analysis}

All statistical analysis were performed with commercially available programme (SPSS 22$)^{7}$. Nonparametric datas were evaluated with Kruskal-Wallis tests. If necessary binary comparisons were made using the Mann-Withney U test. Statistical significance of the changes in parameters in each anesthetic group over time were examined with Friedman test. Binary comparisons were made using the Wilcoxon test.

Reflex parameters were analyzed with Chisquare test. Statistical significance of the changes in parameters in each anesthetic group over time were 
examined with Cochran Q test. Binary comparisons were performed using the McNEmar test, if required.

\section{RESULTS}

The average age of the dogs in the study was 10.83. All of the dogs were anesthetized in a few seconds with intravenous injection of propofol or alphaxalone.

Geriatric dogs were anesthetized for a variety of clinical reasons, concerning laparatomy $(12.5 \%)$, orthopedic $(7.5 \%)$, soft tissue $(60 \%)$, dental $(10 \%)$ and ophthalmologic surgery (10\%). Duration of anesthesia was $94.44( \pm 12.6)$ for group I, 81 $( \pm 10.54)$ for group II, 93.88 $( \pm 11.6)$ for group III and $64.5( \pm 3.97) \mathrm{min}$ for group IV.

\section{Reflex parameters}

The difference between the disappearance times of ear, tail, front pedal, rear pedal and pupillary reflexes of anesthesia groups was not significant (Table 1). The mean recovery time of the alphaxalone-sevoflorane group was longer and statistically significant than the other groups $(P<0.05)$. Recovery period was $6 \pm$ $2 \mathrm{~min}$ in group $1,4.6 \pm 1.4$ in group $2,3.7 \pm 1.2 \mathrm{~min}$ in group 3 and $9.7 \pm 3.1 \mathrm{~min}$ in group 4 .

\section{Complications}

A dog anesthetized with propofol-isoflurane was euthanized because of the large tumoral mass who can not be surgically removed. And a dog anesthetized with alphaxalone-isoflurane with a large tumoral mass in mesentery died in $60^{\text {th }}$ min of anesthesia due to respiratory arrest.

Arrhytmia was detected in two patients at 60 min after recovery with alphaxalone-isoflurane anesthesia. This two dogs were anesthezied for cataract surgery.

Five geriatric dogs underwent mastectomy, two with propofol-isoflurane, three with propofol- sevoflurane anesthesia, however none of them provided adequate analgesia.

The effect of anesthesia on physiological parameters

The effects of anesthesia groups on body temperature and heart rate were not significantly different. However in all groups $\mathrm{T}$ showed a statistically significant decrease compared to $0 . \min (P<0.001)$. There were statistically significant differences between the groups in respiratory rate and haemoglobin oxygen saturation $(P<0.05)$ [Table 2].

\section{The effect of anesthesia on hematological parameters}

Hemoglobin, leukocyte and platelet levels were examined in each group, the difference according to time was not significant. The effects of different anesthesia groups on erythrocytes and hemoglobin levels were examined, a lower values (below the physiological limit) were obtained in the alphaxalone-sevoflurane group at 15 th min compared to the other groups $(P<$ 0.05) [Table 3].

\section{The effect of anesthesia on serum biochemistry}

When the effect of different anesthesia types on serum ALT level was examined, it was determined that lower values were obtained within the physiological limits of the alphaxalone-sevoflurane group compared to other anesthesia groups at $30^{\text {th }}$ and $60^{\text {th }}$ min after recovery, and that the difference was statistically significant $(P<0.05)$. However, the mean ALT level before anesthesia in this group was lower than the other groups.

The difference between anesthesia groups at 30 th and $60^{\text {th }}$ min after recovery on the serum AST level was not significant compared to the preanesthetic period (Table 4).

Serum urea and creatinine concentrations were not significantly different in the four groups.

Table 1. Reflexes, total anesthesia and surgical anesthesia periods of groups.

\begin{tabular}{ccccc}
\hline Parameter & \multicolumn{4}{c}{ Anesthesia Groups } \\
\cline { 2 - 5 } $\bar{x} S_{\bar{x}}$ & 1 & 2 & 3 & 4 \\
\hline Standing reflex dissaparence (s) & $5.77 \pm 1.92$ & $5.10 \pm 1.61$ & $6.66 \pm 0.65$ & $7.00 \pm 0.70$ \\
Ear reflex dissaparence (min) & $5.42 \pm 1.80$ & $5.56 \pm 1.75$ & $5.10 \pm 1.70$ & $5.90 \pm 1.86$ \\
Tail reflex dissaparence (min) & $5.90 \pm 1.96$ & $6.85 \pm 2.16$ & $6.04 \pm 2.01$ & $6.13 \pm 1.93$ \\
Front pedal reflex dissaparence (min) & $4.00 \pm 1.26$ & $4.80 \pm 1.51$ & $4.66 \pm 1.55$ & $4.10 \pm 1.29$ \\
Rear pedal reflex dissaparence (min) & $4.76 \pm 1.58$ & $4.33 \pm 1.37$ & $4.20 \pm 1.40$ & $4.97 \pm 1.65$ \\
Pupillary reflex reflex dissaparence (min) & $47.03 \pm 15.67$ & $57.97 \pm 18.34$ & $41.55 \pm 13.85$ & $44.18 \pm 13.98$ \\
Total anesthesia period (min) & $94.44 \pm 12.60$ & $81.00 \pm 10.54$ & $93.88 \pm 11.60$ & $64.50 \pm 3.97$ \\
Surgical anesthesia period (min) & $88.44 \pm 29.48$ & $76.40 \pm 24.17$ & $85.66 \pm 28.55$ & $58.80 \pm 18.60$ \\
Recovery time (min) & $6.00 \pm 2.00^{\mathrm{A}}$ & $4.60 \pm 1.45^{\mathrm{A}}$ & $3.70 \pm 1.23^{\mathrm{A}}$ & $9.70 \pm 3.09^{\mathrm{B}}$ \\
\hline
\end{tabular}

s: second; min: minutes. ${ }^{\mathrm{A}, \mathrm{B}}$ Different letters in the same rows are statistically significant $(P<0.05)$. 


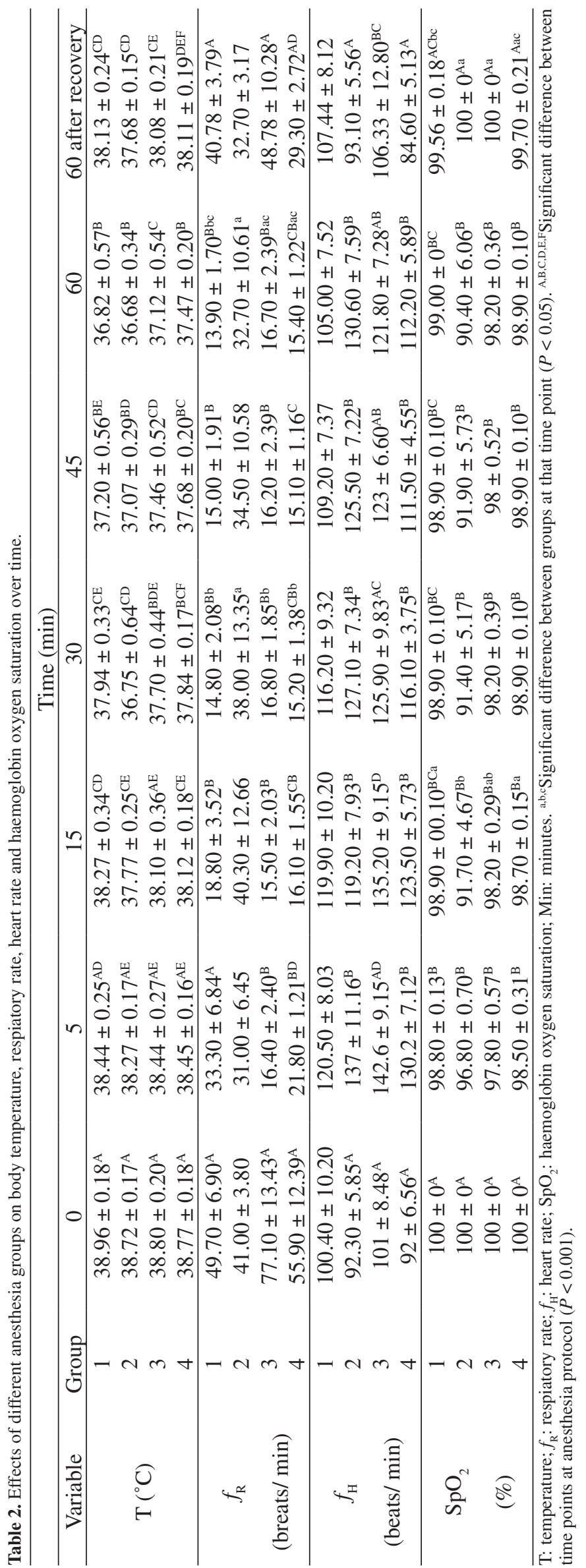


Z.B. Şen \& N. Kiliç. 2018. General Anesthesia in Geriatric Dogs with Propofol-Isoflurane, Propofol-Sevoflurane, Alphaxalone-Isoflurane, Alphaxalone-Sevoflurane andTheir Comparison of Biochemical...

ActaScientiae Veterinariae.46: 1519.

Table 3. Effects of different anesthesia groups on hemoglobin, erythrocytes, leukocyte, hematocrit and platelet levels over time.

\begin{tabular}{|c|c|c|c|c|c|c|c|}
\hline & & & & Time (min) & & & \\
\hline Variable & Group & 0 & 15 & 30 & 45 & 60 & 60 after recovery \\
\hline \multirow{4}{*}{$\begin{array}{c}\mathrm{Hb} \\
(\mathrm{g} / \mathrm{dL})\end{array}$} & 1 & $11.81 \pm 2.01^{\mathrm{A}}$ & $11.27 \pm 1.52^{\mathrm{AD}}$ & $10.39 \pm 1.27^{\mathrm{BCD}}$ & $9.66 \pm 1.17^{\mathrm{BCD}}$ & $9.59 \pm 1.15^{\mathrm{BCD}}$ & $10.90 \pm 1.63^{\mathrm{AC}}$ \\
\hline & 2 & $14.07 \pm 1.32^{\mathrm{A}}$ & $11.38 \pm 1.08^{\mathrm{CD}}$ & $11.93 \pm 1.54^{\mathrm{CD}}$ & $10.10 \pm 1.14^{\mathrm{CB}}$ & $9.60 \pm 0.80^{\mathrm{B}}$ & $12.07 \pm 0.74^{\mathrm{AD}}$ \\
\hline & 3 & $14.72 \pm 0.93^{\mathrm{AD}}$ & $12.77 \pm 0.91^{\mathrm{AC}}$ & $11.95 \pm 1.01^{\mathrm{BC}}$ & $11.73 \pm 1.13^{\mathrm{B}}$ & $11.58 \pm 1.14^{\mathrm{B}}$ & $13.23 \pm 0.67^{\mathrm{BCD}}$ \\
\hline & 4 & $14.62 \pm 1.14^{\mathrm{A}}$ & $9.87 \pm 0.62^{\mathrm{BC}}$ & $9.35 \pm 0.51^{\mathrm{B}}$ & $9.29 \pm 0.58^{\mathrm{B}}$ & $9.51 \pm 0.63^{\mathrm{B}}$ & $12.18 \pm 0.75^{\mathrm{AC}}$ \\
\hline \multirow{4}{*}{$\begin{array}{c}\mathrm{RBC} \\
\left(10^{2} / \mathrm{L}\right)\end{array}$} & 1 & $5.25 \pm 0.73^{\mathrm{AC}}$ & $4.90 \pm 0.46^{\mathrm{BCa}}$ & $4.59 \pm 0.32^{\mathrm{B}}$ & $4.29 \pm 0.30^{\mathrm{B}}$ & $4.29 \pm 0.30^{\mathrm{B}}$ & $4.71 \pm 0.52^{\mathrm{B}}$ \\
\hline & 2 & $6.06 \pm 0.53^{\mathrm{AD}}$ & $5.06 \pm 0.48^{\mathrm{CDa}}$ & $5.08 \pm 0.62^{\mathrm{BD}}$ & $4.37 \pm 0.50^{\mathrm{BD}}$ & $4.12 \pm 0.39^{\mathrm{B}}$ & $5.21 \pm 0.34^{\mathrm{CD}}$ \\
\hline & 3 & $6.23 \pm 0.46^{\mathrm{AC}}$ & $5.50 \pm 0.43^{\mathrm{ABa}}$ & $5.19 \pm 0.50^{\mathrm{B}}$ & $5.08 \pm 0.51^{\mathrm{B}}$ & $4.98 \pm 0.53^{\mathrm{B}}$ & $5.82 \pm 0.24^{\mathrm{BC}}$ \\
\hline & 4 & $5.54 \pm 0.57^{\mathrm{A}}$ & $3.68 \pm 0.37^{\mathrm{Bb}}$ & $3.71 \pm 0.30^{\mathrm{B}}$ & $3.52 \pm 0.37^{\mathrm{B}}$ & $3.71 \pm 0.33^{\mathrm{B}}$ & $4.55 \pm 0.43^{\mathrm{A}}$ \\
\hline \multirow{2}{*}{ WBC } & 1 & $17.88 \pm 5.43^{\mathrm{AB}}$ & $16.05 \pm 3.99^{\mathrm{BC}}$ & $15.44 \pm 4.08^{\mathrm{B}}$ & $15.90 \pm 4.93^{\mathrm{B}}$ & $15.04 \pm 4.76^{\mathrm{B}}$ & $15.82 \pm 5.09^{\mathrm{BC}}$ \\
\hline & 2 & $14.65 \pm 1.54^{\mathrm{A}}$ & $10.69 \pm 2.03^{\mathrm{DC}}$ & $9.49 \pm 1.88^{\mathrm{D}}$ & $8.70 \pm 1.70^{\mathrm{D}}$ & $11.47 \pm 2.22^{\mathrm{DB}}$ & $14.85 \pm 2.41^{\mathrm{ABC}}$ \\
\hline \multirow{2}{*}{$\begin{array}{c}(1000 / \\
\left.\mathrm{mm}^{3}\right)\end{array}$} & 3 & $15.17 \pm 4.03^{\mathrm{A}}$ & $12.24 \pm 3.25^{\mathrm{B}}$ & $10.73 \pm 2.33^{\mathrm{B}}$ & $10.73 \pm 2.78^{\mathrm{B}}$ & $10.30 \pm 2.73^{\mathrm{B}}$ & $14.20 \pm 4.33^{\mathrm{A}}$ \\
\hline & 4 & $11.05 \pm 1.47^{\mathrm{A}}$ & $9.25 \pm 0.80^{\mathrm{B}}$ & $9.06 \pm 0.91^{\mathrm{B}}$ & $8.27 \pm 0.80^{\mathrm{B}}$ & $8.36 \pm 0.73^{\mathrm{B}}$ & $11.02 \pm 1.12^{\mathrm{A}}$ \\
\hline \multirow{2}{*}{ HCT } & 1 & $36.65 \pm 5.07^{\mathrm{AC}}$ & $34.30 \pm 3.26^{\mathrm{BCa}}$ & $31.99 \pm 2.28^{\mathrm{BC}}$ & $29.89 \pm 2.27^{\mathrm{B}}$ & $29.80 \pm 2.22^{\mathrm{B}}$ & $34.05 \pm 3.94^{\mathrm{BC}}$ \\
\hline & 2 & $40.31 \pm 3.51^{\mathrm{A}}$ & $33.89 \pm 3.25^{\mathrm{CDa}}$ & $33.63 \pm 4.14^{\mathrm{BDE}}$ & $29.19 \pm 3.46^{\mathrm{BDE}}$ & $27.35 \pm 2.46^{\mathrm{B}}$ & $34.58 \pm 2.00^{\mathrm{CE}}$ \\
\hline \multirow[t]{3}{*}{$(\%)$} & 3 & $41.14 \pm 3.22^{\mathrm{AC}}$ & $36.06 \pm 2.61^{\mathrm{BCa}}$ & $33.82 \pm 3.15^{\text {В }}$ & $33.37 \pm 3.48^{\mathrm{B}}$ & $32.51 \pm 3.50^{\mathrm{B}}$ & $37.95 \pm 2.00^{\mathrm{BC}}$ \\
\hline & 4 & $37.62 \pm 3.69^{\mathrm{A}}$ & $24.84 \pm 2.34^{\mathrm{Bb}}$ & $25.19 \pm 2.03^{\mathrm{B}}$ & $23.40 \pm 2.27^{\mathrm{B}}$ & $25.07 \pm 2.16^{\mathrm{B}}$ & $30.88 \pm 2.83^{\mathrm{A}}$ \\
\hline & 1 & $448.80 \pm 83.77$ & $432.80 \pm 52.10$ & $373.50 \pm 53.60$ & $433.50 \pm 51.76$ & $509.5 \pm 129.58$ & $443.88 \pm 88.72$ \\
\hline \multirow{3}{*}{$\begin{array}{c}\text { PLT } \\
\left(10^{3} / \mu \mathrm{L}\right)\end{array}$} & 2 & $409.60 \pm 59.16$ & $365.00 \pm 54.16$ & $372.40 \pm 53.70$ & $341.80 \pm 43.88$ & $393.30 \pm 57.47$ & $450.20 \pm 62.13$ \\
\hline & 3 & $459.80 \pm 60.59^{\mathrm{A}}$ & $434.70 \pm 60.84^{\mathrm{AC}}$ & $410.00 \pm 56.80^{\mathrm{AC}}$ & $388.60 \pm 55.46^{\mathrm{BC}}$ & $358.90 \pm 49.29^{\mathrm{B}}$ & $422.00 \pm 54.56^{\mathrm{AC}}$ \\
\hline & 4 & $412.80 \pm 54.68^{\mathrm{A}}$ & $357.20 \pm 45.45^{\mathrm{BCD}}$ & $352.40 \pm 41.18^{\mathrm{BC}}$ & $309.10 \pm 48.83^{\mathrm{B}}$ & $324.3 \pm 31.52^{\mathrm{ABC}}$ & $399.60 \pm 55.33^{\mathrm{AD}}$ \\
\hline
\end{tabular}

HB: hemoglobin; RBC: erythrocytes; WBC: leukocyte; HCT: hematocrit; PLT: platelet; Min: minutes. ${ }^{\text {a,b }}$ Significant difference between groups at that time point $(P<0.05)$. A,B,C,D,E Significant difference between time points at anesthesia protocol $(P<0.05)$.

Table 4. Effects of different anesthesia groups on ALT, AST, urea and creatinine levels over time.

\begin{tabular}{ccccc}
\hline \multicolumn{5}{c}{ Time $(\mathrm{min})$} \\
\hline Variable & Group & 0 & 30 & 60 after recovery \\
\hline & 1 & $56.30 \pm 11.16^{\mathrm{a}}$ & $47.10 \pm 10.03^{\mathrm{a}}$ & $56.11 \pm 9.92^{\mathrm{a}}$ \\
$\mathrm{ALT}$ & 2 & $60.85 \pm 10.69^{\mathrm{Aa}}$ & $32.49 \pm 5.97^{\mathrm{Ba}}$ & $42.66 \pm 11.85^{\mathrm{Bab}}$ \\
$(\mathrm{U} / \mathrm{L})$ & 3 & $67.31 \pm 18.63^{\mathrm{a}}$ & $44.75 \pm 8.44^{\mathrm{a}}$ & $74.37 \pm 17.27^{\mathrm{a}}$ \\
& 4 & $31.74 \pm 6.51^{\mathrm{b}}$ & $20.45 \pm 1.33^{\mathrm{b}}$ & $25.21 \pm 2.52^{\mathrm{b}}$ \\
\hline & 1 & $26.10 \pm 6.12$ & $17.40 \pm 3.50$ & $21.78 \pm 6.66$ \\
$\mathrm{AST}$ & 2 & $57.59 \pm 19.73$ & $23.13 \pm 5.45$ & $39.14 \pm 11.77$ \\
$(\mathrm{U} / \mathrm{L})$ & 3 & $48.85 \pm 11.23$ & $29.96 \pm 3.40$ & $74.37 \pm 24.68$ \\
& 4 & $33.71 \pm 7.48^{\mathrm{AC}}$ & $18.03 \pm 2.59^{\mathrm{B}}$ & $20.74 \pm 3.08^{\mathrm{BC}}$ \\
\hline & 1 & $19.77 \pm 4.61^{\mathrm{a}}$ & $19.72 \pm 4.37$ & $19.26 \pm 4.94$ \\
Urea & 2 & $29.35 \pm 6.75^{\mathrm{a}}$ & $35.09 \pm 9.65$ & $33.87 \pm 8.73$ \\
$(\mathrm{mg} / \mathrm{dL})$ & 3 & $40.23 \pm 6.38^{\mathrm{b}}$ & $45.14 \pm 13.12$ & $45.14 \pm 13.12$ \\
& 4 & $27.72 \pm 1.99^{\mathrm{a}}$ & $26.86 \pm 0.99$ & $23.96 \pm 2.86$ \\
\hline \multirow{3}{*}{ Creatinine } & 1 & $0.73 \pm 0.12^{\mathrm{A}}$ & $0.65 \pm 0.13^{\mathrm{A}}$ & $0.85 \pm 0.16^{\mathrm{B}}$ \\
$(\mathrm{mg} / \mathrm{dL})$ & 3 & $1.02 \pm 0.18$ & $0.52 \pm 0.09$ & $0.60 \pm 0.11$ \\
& 3 & $0.78 \pm 0.05$ & $0.81 \pm 0.04$ & $0.90 \pm 0.18$ \\
\hline
\end{tabular}

ALT: alanine aminotransferse; AST: aspartate aminotransferase; Min: minutes. ${ }^{\text {abb }}$ Significant difference between groups at that time point $(P<0.05)$. ${ }^{\mathrm{A}, \mathrm{B}, \mathrm{C}}$ Significant difference between time points at anesthesia protocol $(P<0.05)$. 


\section{DISCUSSION}

In a study, the anesthetic efficacy and cardiopulmonary effects of propofol with alphaxalone in dogs is compared. Immediately after the administration of both medications, the patients were intubated and provided adequate induction of anesthesia [2]. Similarly the entubation can be done within $1 \mathrm{~min}$ after the end of injection of alphaxalone [9]. Induction was good-excellent in a research investigating the effects of different doses of alphaxalone [18]. Our study suggests that the induction provided by propofol and alphaxalone is adequate, smooth and similar.

The mean duration of anesthesia recovery was $6.0 \pm 2$ in group $1,4.6 \pm 1.45$ in group $2,3.7 \pm 1.23$ in group 3 and $9.7 \pm 3.09 \mathrm{~min}$ in group 4 . In group 4 recovery was longer than other groups and statistically significant $(P<0.05)$. The reason is in this group a geriatric dog's recovery takes $60 \mathrm{~min}$ to raise the average of the group. In a study, the effects of sevoflurane and isoflurane anesthesia on cardiovascular system in dogs treated with experimental laparotomy is investigated. The recovery was faster with sevoflurane [3]. In another study the effects of sevoflurane, isoflurane and halothane on hemodynamic parameters and anesthesia recovery is compared. For 2 MAC, recovery was shorter with isoflurane, then sevoflurane and then halothane [21]. In our research, the recovery is shorter in the isoflurane treated groups than in the sevoflurane treated groups.

All anesthesia groups caused a decrease in body temperature below the physiological limits. However, there was no significant difference between the groups.

The effect of different groups on heart rate was examined, the difference between them was not significant. In ovariohysterectomy operation on dogs total intravenous anesthesia with alphaxalone and propofol is performed. According to this research, the increase on heart rate due to alphaxalone and propofol was not statistically significant and the cardiopulmonary effects of both were similar [28]. Heart rate was increased with desflurane, sevoflurane, isoflurane, enflurane and halothane by concentration [20]. We can say that the increase in heart rate may be caused by both alphaxalone and propofol, and isoflurane and sevoflurane. In our research, two patients anesthetised with alphaxalone-isoflurane had arrhythmia in $60 \mathrm{~min}$ after recovery. Researchers investigated the effect of alphaxalone and etomidate on cardiopulmonary parameters in dogs, and none of the patients with alphaxalone had arrhythmia [25]. Isoflurane anesthesia, did not cause any heart rhythm disturbance in dogs. However, preanesthesics and anesthetics may cause changes in cardiac autonomy and result in important or unimportant forms of arrhythmias [12]. Isoflurane does not sensitize myocardium to catecholamines [27]. Different studies have demonstrated cardioprotective effect of isoflurane on myocardial ischemia and reperfusion injury by increasing diastolic function $[13,29,31]$. However, the heart reserve of geriatric animals is reduced. This can cause changes in the response to anesthetic drugs [6]. Arrhythmia, which occurs in two cases in our study, is thought to be caused by the geriatric nature of the patients.

The respiratory rate showed a statistically significant decrease $(P<0.001)$ at the $15^{\text {th }} \mathrm{min}$ in the propofol-isoflurane group and at the $5^{\text {th }} \mathrm{min}$ in the alphaxalone-isoflurane and alphaxalone-sevoflurane groups. These declines were within physiological limits. Respiratory rate did not change significantly in the group receiving propofol-sevoflurane anesthesia, but the recorded datas were above the physiological limit. Hemodynamic parameters in dogs undergoing sevoflurane, isoflurane and halothane anesthesia are evaluated in a research and three anesthetic agents caused a statistically significant decrease in respiratory rate $(P<0.05)[21]$. In comparison of the effects of propofol and alphaxalone on dogs, a decrease in the physiological borderline in respiratory rate in both anesthesia protocols is found [28]. In the light of these studies and the results obtained in our research, it has been concluded that alphaxalone, propofol, sevoflurane and isoflurane may cause respiratory depression due to dose.

In our research, forty geriatric patients were anesthetised, only one patient had apnea after induction with alphaxalone. During this time the patient was entubated and mechanical ventilation was started. On the 15 th min of the anesthesia, the spontaneous respiration of the patient returned. A researcher examined the effects of intramuscularly applied alphaxolone on rabbits, none of the animals encountered an apnea [22]. The spontaneous ventilation of patients after induction of anesthesia with intravenously given alphaxalone and propofol is evaluated. Propofol has been found to be a higher risk of apnea than alphaxalone [17]. Contrary to 
the studies mentioned, it was thought that in our study, apnea occured in a dog induced with alphaxalone, because of the individual sensitivity of the patient or the rapid intravasculary injection.

Peripheral oxygen saturation $\left(\mathrm{SpO}_{2}\right)$ in all anesthetic protocols showed a statistically significant decrease in the 5th min of anesthesia $(P<0.001)$. Unlike the other groups, hypoxia $\left(\mathrm{SpO}_{2}<92\right)$ was observed in the propofol-sevoflurane anesthesia until the patients recovery from the 15 th min. Isoflurane and sevoflurane anesthesia in dogs is compared, $\mathrm{SpO}_{2}$ was below $96 \%$ (hypoxic onset) in patients with both anesthetic agents. However, since blood gas analysis is not carried out in the study, it has been argued that this hypoxic value may be caused by pulsoximeter [4]. But in our study the presence of hypoxia only in the propofol-sevoflurane group does not support this opinion.

At $65^{\text {th }}$ min of anesthesia, a dog was euthanized because of the size of the abdominal tumoral mass and the lack of possibility of extirpation. A patient died due to heart and respirotary arrest in $60^{\text {th }}$ min of anesthesia. There was a big tumoral mass in this patient that involved mesentery and intestines. Reported anesthesiarelated mortality is $0.17 \%$ in healthy dogs and $1.33 \%$ in unwell dogs [5]. The effect of age on perianesthetic morbidity and mortality in dogs is investigated in a study, suggesting that the mortality risk for geriatric dogs is twice as much as for young animals [15]. In our research, mortality was consistent with the abovementioned literature and does not imply the reliability of the anesthetics we use.

We performed mastectomy in 5 out of 40 patients in the study. It was found that all the dogs who underwent mastectomy did not have sufficient analgesia during the operation. Two of these patients were anesthetized with propofol-isoflurane and 3 with propofol-sevoflurane. For this reason, it has been concluded that analgesics should be added to the anesthesia protocol during painful procedures.

According to our study, the anesthesia protocols did not significantly affect hemoglobin and leukocyte levels over time. In assessing hematocrit and erythrocyte levels of anesthesia groups according to time, there was a statistically significant difference $(P<0.05)$ in the alphaxalone-sevofluran group at 15 $\min (P<0.05)$ and below the physiological limit. Propofol-sevoflurane and alphaxalone-sevoflurane anesthesia caused a statistically significant decrease in hematocrit value at $15^{\text {th }} \min (P<0.001)$. In the propofol-isoflurane group, this value showed a statistically significant decrease at $45^{\text {th }}$ min compared to baseline $(P<0.05)$. Below the physiological limit. The alphaxalone-isoflurane protocol resulted in a statistically significant decrease $(P<0.05)$ in the hematocrit value below the physiological limit at the 30th min compared to the baseline. Exept the alphaxalone-isoflurane group the hematocrit value was below the physiological limit at $60 \mathrm{~min}$ after recovery. Unlike our study, a researcher reported that haematocrit before and after anesthesia in geriatric dogs is within physiological limits [16]. According to a research there was no correlation between blood propofol concentration and hematocrit value [11]. But there was no operative intervention in one of the mentioned studies, and the hematocrit value of all patients was not evaluaed at in the other.

The effect of different anesthesia groups on the platelet concentration in consistent with time was not statistically significant.

ALT level in different anesthesia groups was assessed, serum ALT levels were lower at $0,30^{\text {th }}$ and $60 \mathrm{~min}$ after recovery in the alphaxalone-sevofluran group $(P<0.05)$ than the other groups. Which is why this group has a low serum ALT level in the preanesthetic period.

Serum urea concentration in different anesthesia protocols was evaluated the mean value in the group of alphaxalone-isoflurane at baseline was significantly higher than the other groups $(P<0.05)$. But this was not significant for the study.

In a study isoflurane and sevoflurane were reported to be non-toxic to the liver for dogs [4]. Both anesthetic agents did not have any effect on biochemical parameters in dogs [3]. There is no difference between the effects of sevoflurane and isoflurane in patients with renal insufficiency. Both anesthetic agents do not impair renal function in patients with renal insufficiency [7]. The parameters related to liver and kidney in our study are in parallel with the findings of the above mentioned research. It is understood that isoflurane and sevoflurane do not impair liver and kidney function in this direction.

As a result, it has been determined that alphaxalone and propofol provide adequate and smooth induction of anesthesia in geriatric dogs. It was observed that the depth and duration of propofol- 
isoflurane, propofol-sevoflurane, alphaxalone-isoflurane, alphaxalone-sevoflurane-induced anesthesia were sufficient in terms of surgical interventions. However, it was concluded that the anesthetics used did not provide analgesia in painful operations, so it would be appropriate to use analgesics in the pre or intraoperative period.

The recovery of geriatric dogs from different anesthesia combinations was of good quality. Patients anesthetised with isoflurane were found to wake up faster than those who received sevoflurane.

It was found that the anesthetics used decreased the body temperature below the physiological limit. During perianesthetic period, all geriatric patients should be monitored and the possible complications should be avoided such as hypothermia, hypoxia or apnea.

\section{CONCLUSIONS}

In conclusion, safe anesthesia was provided by isoflurane or sevoflurane after induction of propofol or alphaloxone in geriatric dogs. Analgesics should be added to the anesthesia protocol during painful procedures.

\section{MANUFACTURERS}

${ }^{1}$ Fresenius Kabi Ilac Türkiye. Istanbul, Turkey.

${ }^{2}$ Jurox Pty Limited Company. Rutherford, NSW, Australia.

${ }^{3}$ Adeka Ilaç Sanayi ve Ticaret Anonim Şirketi. Istanbul, Turkey.

${ }^{4}$ Abbvie Tıbbi Ilaçlar Sanayi ve Ticaret ve Limited Şirketi. Istanbul, Turkey.

${ }^{5}$ Pfizer Türkiye. Istanbul, Turkey.

${ }^{6}$ Roche Diagnostics Türkiye. Istanbul, Turkey.

${ }^{7}$ SPSS Inc. Chicago, IL, USA.

Acknowledgements. The autors would like to acknowledge the assistance of the surgery departement staff and veterinary students of the University of Adnan Menderes in data collection and the Adnan Menderes University Scientific Research Foundation for financial support. The autors do not have potential conflicts of interest to declare. This research was supported by Adnan Menderes University Research Fund. Project Number: VTF-15013

Ethical approval. The study was a prospective, specific and comparative clinical trial which was approved by the Adnan Menderes University Ethics Committee (No.64583101/2014/007). Each dog owner consented to the anesthetic procedure the dog was to undergo.

Declaration of interest. The authors report no conflicts of interest. The authors alone are responsible for the content and writing of paper.

\section{REFERENCES}

1 Albertson T.E., Walby W.F. \& Joy R.M. 1992. Modification of GABA-mediated inhibition by various injectable anesthetics. Anesthesiology. 77: 488-499.

2 Ambros B., Duke-Novakovski T. \& Pasloske K.S. 2008. Comparison of the anesthetic efficacy and cardiopulmonary effects of continuous rate infusions of alfaxalone-2-hydroxypropyl- $\beta$ - cyclodextrin and propofol in dogs. American Journal of Veterinary Research. 69(11): 1391-1398.

3 Apaydın N. \& Kibar M. 2008. Deneysel laparatomi uygulanan köpeklerde sevofluran ve isofluran anestezisinin kardiyovasküler sistem üzerine etkileri. Sağllk Bilimleri Dergisi. 17(3): 162-167.

4 Boulestin A.S.M. 2004. L'anesthésie du chien au sevoflurane étude comparée avec l'isoflurane. 66p. Ecole Nationale Vétérinaire de Toulouse. Thèse d'exercice, Université Paul Sabatier - Toulouse III. Toulouse, France.

5 Brodbelt D.C., Blissitt K.J., Hammond R.A., Neath P.J., Young L.E., Pfeiffer D.U. \& Wood J.L.N. 2008. The risk of death: the confidential enquiry into perioperative small animal fatalities. Veterinary Anaesthesia and Analgesia. 35: 365-373.

6 Carpenter R.E., Pettifer G.R. \& Tranquilli W.J. 2005. Anesthesia for geriatric patients. Veterinary Clinics Small Animal Practice. 35: 571-580.

7 Conzen P.F., Kharasch E.D., Czerner S.F.A., Artru A.A., Reichle F.M., Michalowski P., Rooke A., Weiss B.M. \& Ebert T.J. 2002. Low-flow sevoflurane compared with isoflurane anesthesia in patients with stable renal insufficiency. Anesthesiology. 97(3): 578-584.

8 Dowling P.M. 2005. Geriatric pharmacology. Veterinary Clinics of Small Animal Practice. 35: 557-569.

9 Ferré P.J., Pasloske K., Whittem T., Ranasinghe M.G., Li Q. \& Lefebvre H.P. 2006. Plasma pharmacokinetics of alfaxalone in dogs after an intravenous bolus of Alfaxan-CD RTU. Veterinary Anaesthesia and Analgesia. 33: 229-236.

10 Fortney W.D. 2011. Geriatri ve Ya lanma. In: Hoskins J.D. (Ed). Kedi ve köpeklerde Geriatri ve Gerontoloji. 2nd edn. Turkey: Medipress, pp.1-6. 
11 Goodchild C.S. \& Serrao J.M. 1989. Cardiovascular effects of propofol in the anaesthetized dog. British Journal of Anaesthesiology. 63: 87-92.

12 Güzel Ö. \& Perk E.C. 2002. Köpeklerde genel anestezi prosedürü ve intraoperatif periyotta rastlanan kardiyak ritm bozukluklarının tanı ve sağaltımı. İstanbul Üniversitesi Veteriner Fakültesi Dergisi. 28(2): 381-401.

13 Hanley P.J., Ray J., Brandt U. \& Daut J. 2002. Halothane, isoflurane and sevoflurane inhibit NADH: ubiquinone oxidoreductase (complex I) of cardiac mitochondria. Journal of Physiology. 544(3): 687-693.

14 Harrison N.L. \& Simmonds M.A. 1984. Modulation of the GABA receptor complex by a steroid anaesthetic. Brain Research. 323: 287-292.

15 Hosgood G. \& Scholl D.T. 1998. Evaluation of age as a risk factor for perianesthetic morbidity and mortality in the dog. The Journal of Veterinary Emergency and Critical Care. 8(3): 222-236.

16 Joubert K.E. 2007. Pre-anaesthetic screening of geriatric dogs. Journal of the South African Veterinary Association. 78(1): 31-35.

17 Keates H. \& Whittem T. 2012. Effect of intravenous dose escalation with alfaxalone and propofol on occurrence of apnoea in the dog. Research in Veterinary Science.93: 904-906.

18 Muir W., Lerche P., Wiese A., Nelson L., Pasloske K. \& Whittem T. 2008. Cardiorespiratory and anesthetic effects of clinical and supreclinical doses of alfaxalone in dogs. Veterinary Anaesthesia and Analgesia. 35: 451-462.

19 Paddleford R.R. 2011. Anestezi. In: Hoskins J.D. (Ed). Kedi ve Köpeklerde Geriatri ve Gerontoloji. 2nd edn. Turkey: Medipress, pp.73-85.

20 Picker O., Scheeren T.W.L. \& Arndt O. 2001. Inhalation anaesthetics increase heart rate by decreasing cardiac vagal activity in dogs. British Journal of Anaesthesia. 87(5): 748-754.

21 Polis I., Gasthuys F., Ham Van L. \& Laevens H. 2001. Recovery times and evaluation of clinical hemodynamic parameters of sevoflurane, isoflurane and halothane anaesthesia in mongrel dogs. Journal of Veterinary Medicine. A48: 401-411.

22 Poumeyrol S.M.S. 2012. Etude clinique des effets de l'alfaxalone en injection intra-musculaire chez le lapin. 64p. Ecole Nationale Vétérinaire d' Alfort, Maisons-Alfort. Thèse de Doctorat Vétérinaire. Faculté de Médécine Université de Créteil, Université Paris-Est-Créteil (UPEC), Créteil, France.

23 Pride N.B. 2005. Agening and changes in lung mechanics. European Respiratory Journal. 26: 563-565.

24 Reid J. \& Nolan A.M. 1996. Pharmacokinetics of propofol as an induction agent in geriatric dogs. Research in Veterinary Science. 61: 169-171.

25 Rodriguez J.M., Munoz-Rascon P., Navarette-Calvo R., Gomez-Villamandos R.J., Perez J.M.D., Sarmiento J.A.F., Carmona S.Q. \& Machuca M.M.G. 2012. Comparison of the cardiopulmonary parameters after induction of anaesthesia with alphaxalone or etomidate in dogs. Veterinary Anaesthesia and Analgesia. 39: 357-365.

26 Sadean M.R. \& Glass P.S.A. 2003. Pharmacokinetics in the elderly. Best Practice \& Research Clinical Anaesthesiology. 17(2): 191-205.

27 Seeler D.C., Dodman N.H., Norman W. \& Court M. 1988. Recommended techniques in small animal anaesthesia IV anaesthesia and cardiac disease. British Veterinary Journal. 144: 108-122.

28 Suarez M.A., Dzikiti B.T., Stegmann F.G.\& Hartman M. 2012. Comparison of alfaxalone and propofol administered as total intravenous anaesthesia for ovariohysterectomy in dogs. Veterinary Anaesthesia and Analgesia. 39: 236-244.

29 Symons J.A. \& Myles P.S. 2006. Myocardial protection with volatile anaesthetic agents during coronary artery bypass surgery: a meta-analysis. British Journal of Anaesthesia. 97(2): 127-136.

30 Taboada F.M. \& Murison P.J. 2010. Induction of anaesthesia with alfaxalone or propofol before isoflurane maintenance in cats. Veterinary Record. 167: 85-89.

31 Tanaka K., Ludwig L.M., Kersten J.R., Pagel P.S. \& Warltier D.C. 2004. Mechanisms of cardioprotection by volatile anesthetics. Anesthesiology. 100(3): 707-721.

32 Warne L.N., Beths T., Whittem T., Carter J.E. \& Bauquier S.H. 2015. A review of the pharmacology and clinical application of alfaxalone in cats. The Veterinary Journal. 203: 141-148.

33 Warpechowski P., Santos A.T.L., Pereire P.J.I. \& Lima G.G. 2010. Effects of propofol on the cardiac conduction system. Revista Brasileira de Anestesiologia. 60(4): 438-444. 